\title{
VIOLÊNCIA DOMÉSTICA CONTRA A CRIANÇA E O ADOLESCENTE DIANTE DOS ASPECTOS LACUNOSOS DA LEI 13.010, DE 26.06.2014 (LEI DA PALMADA)
}

\author{
Brenda Gutierres dos Santos ${ }^{1}$, Camila Viríssimo Rodrigues da Silva Moreira²
}

\author{
${ }^{1}$ Acadêmico do Curso de Direito, Centro Universitário de Maringá - UNICESUMAR. \\ brendagutierres10@hotmail.com \\ ${ }^{2}$ Orientadora, Mestre em Direitos da Personalidade pelo Centro Universitátio de Maringá - UNICESUMAR. Pós-graduada em Direito \\ Penal e Processual Penal pela Universidade Estadual de Londrina - UEL. Professora no Centro Universitário de Maringá - \\ UNICESUMAR. camilavrs@hotmail.com
}

RESUMO

\begin{abstract}
O presente artigo visa apresentar uma reflexão sobre a aplicabilidade da Lei 13.010/2014 (Lei da Palmada) no setor da violência doméstica contra a criança e o adolescente, obtendo como ponto de partida a evolução histórica desta, que, como método mais eficaz para "educar", chegou ao Brasil por meio dos jesuítas em suas missões e prevalece até os dias atuais. Como sequência abordando o reconhecimento de crianças e adolescentes na condição de sujeitos de direitos, que se deu no século XX através da Convenção sobre os Direitos da Criança que impôs um sistema de proteção e garantias fundamentados na proteção e cuidados especiais e no melhor interesse da criança e do adolescente. Através disso, a ordem jurídica internacional e interna proíbe toda e qualquer forma de violência contra a criança e o adolescente, e, nesse sentido a Lei da Palmada foi analisada como forma de inclusão do sistema de proteção e garantias contra esse tipo de violência, no entanto a reflexão abordará sua omissão em relação ao "sofrimento psíquico ou moral" e a contradição em torno das expressões "castigo físico" que gere "sofrimento físico", diante do Código Civil que tolera o castigo educativo moderado.
\end{abstract}

PALAVRAS-CHAVES: Castigo; Educação; Lacunas; Omissa; Reflexão.

\section{INTRODUÇÃO}

A violência é um grave e complexo problema que envolve aspectos jurídicos, psicológicos, médicos, pedagógicos e sociais. Crianças e adolescentes estão entre as principais vítimas de violências. No mundo, cerca de 227 crianças e adolescentes, considerando a faixa etária de 0 a 19 anos segundo a Organização Mundial da Saúde OMS, morrem diariamente como resultado de violência interpessoal (CARLOS et al.; 2016). Na maioria das vezes, esta violência ocorre em um espaço de relações de confiança, responsabilidade ou poder - o espaço doméstico. Essa violência pode ser caracterizada como uma ação ou omissão, praticada pelos pais ou responsáveis, causando abuso físico, psicológico e sexual contra a criança e o adolescente (PEGO, 2016), passando assim a se chamar "violência doméstica contra a criança e o adolescente".

Visando concretizar o sistema de produção e suprir a lacuna existente no sistema protetivo brasileiro em matéria de violência contra a criança sobre argumentação educativa e corretiva, foi editada a Lei 13.0100 de 26.06.2014 conhecida como Lei da Palmada, cuja o objetivo seria proibir os castigos físicos às crianças e adolescentes pelos pais ou responsáveis (ALKIMIN, 2016).

Todavia, revela-se omissa, haja vista que não especificou a violência ou castigo psicológico, do mesmo modo que revela-se contraditória ao proibir "castigo físico", não especificando se a proibição aborda o castigo físico ou corporal moderado, estabelecendo um confronto entre o Estatuto da criança e do adolescente - ECA e o Código Civil de 2002 que veda apenas o castigo imoderado (art.1.638 do CC/2002).

Seguindo essa linha de raciocínio, foi abordado a evolução histórica da violência contra a criança e o adolescente; destacando-se a conquista de reconhecimento da condição de sujeitos de direitos com a criação do sistema de proteção e de defesa aos direitos fundamentais infanto-juvenis e de proteção contra toda forma de violência, sob o 
fundamento principiológico da proteção integral e do melhor interesse, incorporados pelo Brasil através da Constituição federal de 1988 e do ECA.

E por fim, foi feita uma análise da lei da Palmada no que refere-se aos avanços inseridos no sistema de proteção e aos aspectos lacunosos e contraditórios dessa lei. Para esse fim, é de grande importância a busca de dados no Direito Penal, o qual é o segmento do ordenamento jurídico que obtém a função de selecionar os comportamentos humanos mais graves e nocivos à coletividade, capazes de colocar em risco valores fundamentais para a convivência social.

\section{MATERIAS E METODOS}

A metodologia aplicada é indutiva, pesquisas em sites e bibliográfica. A primeira etapa da pesquisa foi de cunho bibliográfico e consiste na busca de materiais acadêmicos científicos que discutam: a) Evolução histórica da violência contra a criança e o adolescente; b) Conceito; c) Conquista de reconhecimento destes como sujeitos de direitos; d) O fundamento principiológico da proteção integral e do melhor interesse; e) Aspectos lacunosos e controvertidos da Lei 13.010/2014 (Lei da Palmada).

\section{$3 \quad$ RESULTADOS E DISCUSSÕES}

A história da violência vem percorrendo desde os tempos primórdios, como alegam os livros da história da civilização. Se observarmos o período da escravidão onde os laços culturais estavam implantados na sociedade, evidentemente perceberemos que a cultura demandava os castigos físicos como meio de corrigir e educar (GOMES, 2015).

No Brasil, o uso do castigo físico como método educacional teve sua origem dentre os jesuítas que, durante suas missões, defendiam ser esse um método eficaz de "educar" as crianças indígenas que estavam sendo catequizadas. Dessa maneira, o costume de "bater" foi aceito pela sociedade de forma muito natural, prevalecendo até os dias atuais (CASSIONATO; CASSIONATO; DIAS, 2016). Os efeitos da violência doméstica podem ser muito sérios, ressaltando o fato de que as crianças e adolescentes aprendem com cada situação que vivenciam, seu psicológico é instruído pelo social e o primeiro grupo social que temos contato é a família (ROSAS; CIONEK, 2006).

As principais descobertas foram que a teoria neoconstitucionalista pós-positivista, responsável pela compreensão da importância dos princípios para o Direito, sofreu grande impulso no Brasil. Ronald Dworkin e, posteriormente, Robert Alexy, fundamentaram o neoconstitucionalismo defendendo o princípio como base para a formulação de qualquer norma jurídica. Diante disso, a dignidade humana tornou-se um princípio e, por sua grande importância, foi regulamentado que toda teoria ou norma jurídica criadas devem preservar a exatidão deste (ROSÁRIO, 2010).

É relevante também o princípio do melhor interesse da criança e do adolescente, tal princípio teve sua origem na Inglaterra, com o intuito de proteger aqueles que não podiam proteger a si próprios, ou melhor, que eram juridicamente limitados. O ponto principal do conteúdo deste é a supremacia do interesse do menor sobre o interesse dos genitores ou da família. Em resumo, deve-se preservar aqueles que possuem fragilidades, e os menores claramente se encontram nessa posição (OLIVEIRA, 2014).

A partir disso, como meio do Estado intervir nessas relações interfamiliares e regulamentar o método educacional utilizado, foi editada a Lei 13.0100 de 26.06.2014 conhecida como Lei da Palmada, cuja o objetivo seria proibir os castigos físicos às crianças e adolescentes pelos pais ou responsáveis. Todavia esta revela-se omissa, pois não especificou claramente suas proibições, obrigações e permissões (ALKIMIN, 2016).

A discussão pertinente é voltada a uma reflexão sobre a aplicabilidade da Lei 13.010/2014 Lei da Palmada no setor da violência doméstica contra a criança e o 
adolescente. É evidente que há muitas dúvidas em relação a essa lei. Por esse motivo, é de grande importância a interlocução sobre esse assunto.

\section{CONSIDERAÇÕES FINAIS}

A pesquisa realizada demonstra que a violência doméstica contra a criança e o adolescente, em especial o castigo físico ou tratamento desumano e degradante como forma de educação e correção, mesmo que seja um fato histórico, social e cultural, é uma realidade longe de ser desenraizada do dia a dia da vida da criança e do adolescente de todo o mundo.

Evidentemente, o reconhecimento da condição de sujeitos de direitos e de garantias fundamentais e a implantação de todo sistema de proteção tanto no âmbito internacional como no âmbito interno, contra todas as formas de violência, não é suficiente para o sistema de proteção ter uma ação efetiva, com eliminação do castigo físico e outras formas de violência que interferem à dignidade e integridade da criança e do adolescente.

No entanto, foi editada a Lei 13.0100 de 26.06.2014 conhecida como Lei da Palmada, que busca vedar os castigos físicos às crianças e adolescentes, trazendo um caráter protetivo. Mesmo com todo esse viés protetivo, esta revela-se lacunosa quanto a omissão à agressão psíquica e contraditória ao proibir "castigo físico", não especificando se a proibição aborda o castigo físico ou corporal moderado, trazendo um acareamento entre o Estatuto da criança e do adolescente e o Código Civil de 2002 que veda apenas o castigo imoderado (art.1.638 do CC/2002).

É possível notar que de fato o intérprete, no momento da interpretação da norma, terá que ser cauteloso para obter o equilíbrio da lei positivada e os valores culturais da nossa sociedade em relação a esse método utilizado para "educar". E os pais no momento de educar seus filhos, devem operar o diálogo como método principal de controle e somente em ultima instância devem recorrer ao corporal moderado, como prevê o ECA e o Código Civil de 2002 no art.1.638 que proíbe apenas o castigo imoderado.

\section{REFERÊNCIAS}

ALKIMIN, Maria Aparecida. Uma reflexão em torno da violência doméstica contra a criança e o adolescente diante dos aspectos controvertidos e lacunosos da Lei 13.010, de 26.06.2014 (Lei da Palmada). Revista dos Tribunais, Vol 105, n.964, p. 377405, fev. 2016. Disponível em: <http://www.mpsp.mp.br/portal/page/portal/documentacao e_divulgacao/doc_biblioteca/bibli_servicos_produtos/bibli_boletim/bibli_bol_2006/RTrib_n. 964.14.PDF> Acesso em: 30 de abril de 2019.

CASSIONATO, Andréa Silva Albas; CASSIONATO, Fernando Cézar Lopes; DIAS, José Francisco de Assis. A lei da palmada, a dignidade humana da criança e a intervenção estatal na família. - 1. ed. ebook - Maringá,PR : Vivens, 2016.

CARLOS, D. et al. Violência doméstica contra crianças e adolescentes: olhares sobre a rede de apoio. Rev. Gaúcha Enferm. vol.37 Porto Alegre 2016.

GOMES, Wesllya Cordeiro. Poder familiar: até onde o conflita com a lei da palmada em seu viés normativo e fático. Revista de Direito UNIFACEX, Natal-RN, v.6, n.1, 2015. 
OLIVEIRA, Gabriela Pinto de. As primeiras impressões sobre a "Lei da Palmada", o projeto de lei n 7.672/10. Instituto Três Rios, RJ 2014.

PEGO, Hortencia Aguiar. Lei da Palmada e a violência doméstica contra criança e o adolescente. Disponível em: <https://www.direitonet.com.br/artigos/exibir/8639/Lei-daPalmada-e-a-violencia-domestica-contra-criancas-e-o-adolescentes> Acesso em 29 de abril de 2019.

ROSAS, Fabiane Klazura; CIONEK, Maria Inês Gonçalves Dias. O impacto da violência doméstica contra crianças e adolescentes na vida e na aprendizagem. Conhecimento Interativo, São José dos Pinhais, PR, v. 2, n. 1, p. 10-15, jan./jun. 2006.

ROSÁRIO, Luana Paixão Dantas. O Neoconstitucionalismo, a Teoria dos Princípios e a dimensão ético-moral do Direito. Revista de Informação Legislativa, Brasília a. $47 \mathrm{n}$. 186 abr./jun. 2010. 